Raafat S. Hannallah MD FRCP(C), José K. Rosales MD FRCP(C)

\title{
Experience with parents' presence during anaesthesia induction in children
}

Parents of 50 unprumedicated children were invited to be present during induction of anaesthesia in their children. The presence of the parents resulted in a significant decrease in the number of very upset or turbulent children during the pre-induction and induction periods, when compared to a control group that was induced without the parents' participation. There was no difference in the children's behaviour in the recovery room or at home following surgery. Most parents were calm and supportive during induction, and there were no complications related to their presence. It is concluded that for some preschool children, allowing the parents to support an anxious child during anaesthesia induction can be very effective in relieving anxiety, and minimizes the need for premedication.

Key words ANAESTHESIA: paediatric, outpatient psychological effects.

From the Department of Anaesthesia, Montreal Children's Hospital and McGill University, Montreal, Québec.

Address correspondence to: Dr. R.S. Hannallah, Department of Anesthesiology, Children's Hospital, National Medical Center and George Washington University, 111 Michigan Avenue, N.W., Washington, D.C. 20010 .
Anaesthesia for preschool children is a special challenge. At that age, children are old enough to appreciate the stress of the hospital environment and separation from family. However, their ability to profit from preoperative preparation and develop new social contacts is still very limited. The role of the mother in providing comfort and support while facing any type of stress or new experience is essential during that stage of development.

The increasing popularity of outpatient surgery, and the development of day surgery centres has greatly minimized maternal separation for children undergoing minor surgical procedures. The present study was undertaken to examine the effects of eliminating that separation entirely by allowing the mother to be present with the child during induction of anaesthesia, and immediately upon recovery until discharge from the Day Surgery unit.

\section{Method}

A group of 50 unpremedicated children $1-5$ years old scheduled for outpatient surgery were the subjects of the study. During the preoperative interview, the parents were invited to stay with their child during anaesthesia induction. The decision as to which of the parents would accompany the child was left up to them (Table I). To study 50 cases, we had to approach 54 parents, since four mothers refused the invitation to be present with their children during induction, and are not included in the study. Two of them stated that their children

TABLE 1 Which parent elected to stay

\begin{tabular}{lrr}
\hline & No. & $\%$ \\
\hline Mother only & 39 & 78 \\
Father only & 5 & 10 \\
Both parents & 6 & 12 \\
\hline
\end{tabular}


(both girls age three) were well prepared, and would do well alone; while the other two were apprehensive about watching their children (both boys age four and five) go to sleep.

Anaesthesia was induced by a sleep dose of intravenous thiopenta! (4-6 $\mathrm{mg} \cdot \mathrm{kg}^{-1}$ ) using a 25 gauge scalp vein needle in all cases. Induction took place in a special area immediately adjacent to the operating room and equipped to handle any airway difficulty. Induction of anaesthesia was judged to be technically easy if successful after one attempt at venipuncture; difficult if it required two attempts; and very difficult if it required more than two attempts. When the child was asleep, he was immediately transported to the operating table, and anaesthesia maintained with $\mathrm{N}_{2} \mathrm{O} / \mathrm{O}_{2}$ and halothane. Following surgery, the child was transported to the recovery room; and when fully awake, was joined by his mother or father until discharged home.

The mood of each child was judged on a scale of one to five (Table II) at four stages: (1) waiting room. (2) pre-induction, while being escorted to the induction area, (3) during induction of anaesthesia, (4) postoperatively in the recovery room. Parents' reaction and attitude during induction was also evaluated.

Two weeks following surgery, the parents were contacted, and the child's behaviour at home following discharge was discussed. Questions were based on the "Post-hospitalization behaviour questionnaire" for children compiled by Vernon et al.,' and asking the mother for her free comments.

A comparable group of 50 children in whom anaesthesia induction was performed in the same manner, but without the parents' presence being allowed beyond the waiting area served as the control group. Differences between the two groups were determined using the Chi square test.

\section{TABLE II Children: Behaviour during induction}

(1) Quiet, ca-operative or playful with minimal reaction to venipunchure.

(2) As in (1), but cries with venipuncture.

(3) Disturbed, anxious, crying, responds to gentle approach, but quickly reverts back.

(4) As (3) but does not respond to the anaesthetist

(5) Turbulent. Uncontrollable, even by parents. Does not listen. Screams continuously
TABLE III Age and sex

\begin{tabular}{lcc}
\hline Age & \# With parents & \# Without parents \\
\hline 1 yr & 5 & 6 \\
2 yrs & 9 & 10 \\
3 yrs & 12 & 13 \\
4 yrs & 16 & 11 \\
5 yrs & 8 & 10 \\
Male:Female & $31: 19$ & $33: 17$ \\
\hline
\end{tabular}

TABLE IV Type of surgery

\begin{tabular}{lll}
\hline Operation & Parent present & Nat present \\
\hline Dental & 25 & 20 \\
Herniotomy & 6 & 12 \\
Circumcision & 8 & 7 \\
Ophthalmologic & 5 & 0 \\
Myringatomy & 1 & 6 \\
Other & 5 & 5 \\
TOTAL & 50 & 50 \\
\hline
\end{tabular}

TABLE V Ease of venipuneture

\begin{tabular}{lcc}
\hline & With parent & Without partent \\
\hline Easy (one attempt) & $45(90 \%)$ & $41(82 \%)$ \\
Difficult (two attempts) & $4(8 \%)$ & $9(18 \%)$ \\
Very difficult (>2 attempts) & $1(2 \%)$ & $0(0 \%)$ \\
\hline
\end{tabular}

\section{Results}

The two groups of patients were comparable as far as age, sex and type of surgery (Tables III and IV).

The ease of venipuncture (which can reflect the skill of the anaesthetist, or the lack of struggle by the child) was not different in the two groups (Table V).

The mood of the children was comparable for both groups in the waiting area and during recovery room stay. There was a significant decrease $(\mathrm{p}<$ 0.001 ) in the number of very upset or turbulent children in the group accompanied by parents during the pre-induction and induction periods as compared to the control group (Figure).

The parent's attitude during induction is shown in Table VI.

Delayed response (Children's Behavioural Questionnaire)

There were no significant differences between the two groups with respect to general anxiety and regression, anxiety about sleep, agression towards 

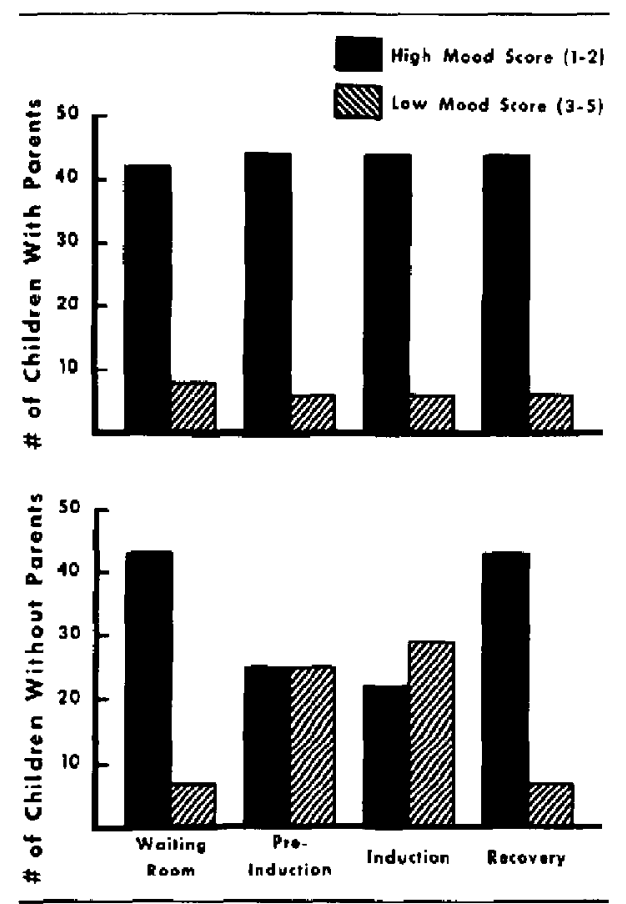

FIGURE Mood of the children before, during, and after induction. See text for details.

TABLE VI Parents' attitude during induction

\begin{tabular}{lc}
\hline Calm, supportive & $38(76 \%)$ \\
Anxious, cried & $12(24 \%)$ \\
Very upset, hysterical, or fainted & $0(0 \%)$ \\
\hline
\end{tabular}

TABLE VII Delayed behavioural questionnaire

\begin{tabular}{lcc}
\hline & With parents & Without parents \\
Symptom grouping & $N(43)$ & $N(4 I)$ \\
\hline General anxiety and regression & $6.97 \%$ & $4.86 \%$ \\
Separation anxiety & $46.49 \%$ & $65.84 \%$ \\
Anxiety about sleep & $65.11 \%$ & $60.97 \%$ \\
Aggression towards authority & $34.87 \%$ & $36.57 \%$ \\
Apathy withdrawal & $13.95 \%$ & $17.06 \%$ \\
\hline
\end{tabular}

authority, separation anxiety, or apathy and withdrawal (Table VII).

\section{Complications}

There were no major or minor complications or side effects attributed to the presence of parents in the induction area.

\section{Discussion}

Anaesthetists, surgeons, paediatricians and psychiatrists are well aware of the potential of psychological trauma in the child who must undergo surgery. ${ }^{2}$ Much of the anxiety encountered by children between one and five years old is related to separation from parents. This separation can be minimized in the preoperative period by the increased utilization of outpatient surgical facilities and by allowing parents of hospitalized children to "room-in" with them from the time the child is admitted to the hospital to the time when he leaves to go to the operating room. While this approach is effective in minimizing maternal separations in the preoperative period, it is more likely to make the child more upset when he is finally taken away from his parents for anaesthesia induction. ${ }^{3}$

A traditional way of avoiding that unpleasant situation was to prescribe beavy doses of premedication to avoid the screaming and resistance that often occurs when any young child is taken away from his parents. ${ }^{4}$ With heavy premedication, the anaesthetic state is in effect being initiated in the parents $^{1}$ presence with the usually long acting premedicant drug.

With the more common use of outpatient surgical facilities, it is becoming more and more desirable to avoid the use of long acting premedicants. It is essential, however, that the goal of premedication (to make the child sleep before separating him from his parents) not be sacrificed.

Our results demonstrate that these goals can be largely achieved by allowing one or both of the parents to stay with the child during induction of anaesthesia. Although no long-term beneficial results were seen in our small sample of patients, a larger number of children, or a longer follow up period, may show different results.

Although there has been a traditional resistance to this concept among anaesthetists, it is becoming now more accepted, and regarded as not entirely unreasonable by many authors. $5,6 *$

There are nonetheless many possible reasons why the anaesthetist may prefer not to have the parents present during anzesthesia induction. The anaesthetist may feel uncomfortable being "watched"

* Kay B. Paediatric anaesthesia without tears. Presented at annual meeting, Association of Anaesthetists of Great Britain and Ireland, London, England, 1966. 
by the parents. What if anything goes wrong? Can the parents be critical? Furthermore there is always the question of dividing one's attention between the child and parents. The anxious parents can possibly make a child even more upset. However, our experience showed that these are not common problems. Parent's selection and education is important. Those who are invited to watch their child's induction must be told precisely what to expect, and should have an escort to take them back to the waiting area as soon as the child is asleep. Parents must agree to leave the induction area at any moment if so asked by the anaesthetist. Unduly anxious or hysterical parents should not be encouraged in the induction area since they can contribute to similar anxiety in their children.

Since induction of anaesthesia is performed outside the operating room, only healthy children presenting for elective surgical procedures should be considered. Infants under one year of age are rarely suitable candidates.

The method of induction can vary according to the preference of the anaesthetist. Although all patients in this study were induced with intravenous thiopental, the use of intramuscular ketamine (1-2 $\mathrm{mg} \cdot \mathrm{kg}^{-1}$ ) or rectal methohexital $\left(25 \mathrm{mg} \cdot \mathrm{kg}^{-1}\right)$ can be appropriate. Unless there are specially equipped induction rooms, or portable anaesthesia machines, the use of an inhalational induction technique is not practical. In all cases, cquipment for airway management must be immediately available.

One of the major factors limiting the more widespread participation of parents during anaesthesia induction in many institutions is the necessity to have specially equipped areas outside the operating room where anaesthesia induction can be safely performed with the parents present. That possibility should be very carefully studied by anyone involved in planning or re-designing an operating room suite.

\section{Acknowledgement}

The authors are grateful for Dr. Saba Boctor for his help with this study, and for Dr. T. Truong for performing the statistical analysis.

\section{References}

1 Vermon D, Schulman J, Foley J. Changes in children's behavior after hospitalization. Amer J Dis Child 1966; 111: 581-93.

2 Eckenhoff $J E$. Relationship of anaesthesia to postoperative personality changes in children. Am J Dis Child 1953; 86: 587-91.

3 Lee JS, Green NM. Parental presence and emotional statc of children prior to surgery. Clinical Pediatrics $1969 ; 8$ : 126-30.

4 Meyers EF, Muravchick $S$. Anesthesia induction technics in pediatric patients: A controlled study of behavioral consequences. Anesth Analg 1977; 56: $538-42$.

5 Smith RM. Anesthesia for Infants and Children. 4 th ed. St. Louis, Mosby (1980).

6 Schulman JL, Foley J, Vernon DT et al. A study of the effects of the mother's presence during anesthesia induction. Pediatrics $1967 ; 39 ; 111-4$.

\section{Résumé}

On a invité les parents de cinquante enfants ageés d'un d cinq ans à être présents pendant l'induction de l'amesthéstie chez leurs enfants. Lorsqu' on compara ce groupe d un groupe-témoin de cinquante patients recevant l'anesthésie sans la participation de leurs parents, on observa que la présence des parents diminua l'agitation et la turbulence de certains enfants pendant la période de pré-induction et pendant l'induction elle-même. On n'observa pas de différence dans l'autitude des enfants dans la salle de réveil ni chez eux. La plupart des parents resterent calmes et encourageants pendant l'induction et ne causèrent pas de complications par leur présence. Nous concluons donc que pour certains enfants d'age pré-scolaire, il serait bon de permettre aux parents d'encourager leurs enfants anxieux pendant l'induction de l'anesthésie. Cela serait efficace afin de soulager l'anxiété et de réduire le besoin d' une prémédication. 